\title{
Ultra-Trace Determination of Phosphate Ion Based on Filtration-Dissolution and Flow-through Spectrophotometric Measurement ${ }^{\dagger}$
}

\author{
Shoji Motomizu*, Joko P. Susanto*, Mitsuko Oshima*, \\ Hiroshi MikaSA** and Yoshikazu HoRI** \\ *Department of Chemistry, Faculty of Science, Okayama University, \\ Tsushimanaka, Okayama 700, Japan \\ **RC Research Laboratory, Tokuyama Co., Ltd, Mikage, Tokuyama 745, Japan
}

\begin{abstract}
A sensitive spectrophotometric method for the determination of ultra-trace amounts of phosphate ion is proposed. The colored ion associate formed between molybdophosphate and Malachite Green (MG) was filtered through a tiny membrane filter (cellulose nitrate; poresize, $1.0 \mu \mathrm{m} ; 9 \mathrm{~mm}$ diameter), dissolved together with the membrane filter in $1 \mathrm{~cm}^{3}$ or less of Methyl Cellosolve; the absorbance of the solution was then measured at $627 \mathrm{~nm}$ with a flow-through system equipped with an autosampler. The absorbance, the standard deviation and the relative standard deviation of the reagent blank were $0.0270,0.0005$ and $1.8 \%$, respectively. A calibration graph was linear over the range from 0.018 to $1.0 \mathrm{ng} \mathrm{cm}^{-3}$ ( $\left.1 \mathrm{ppb}\right)$ of phosphorus using $40 \mathrm{~cm}^{3}$ of sample solutions; the detection limit corresponding to two-times the standard deviation of the reagent blank was $3 \mathrm{ppt}$ of phosphorus. By using the proposed method, phosphate ion in pure water samples were determined.
\end{abstract}

Keywords Phosphate determination, filtration-dissolution, molybdophosphate-Malachite Green ion associate, absorptiometry, flow-through measurement

The determination of ultra-trace phosphorus at subppb levels has become increasingly important in most advanced industrial fields, such as the semiconductor industry, ultra-pure-water suppliers and biomedical suppliers. In fields concerning semiconductors, the method along with an ICP-mass spectrometer (ICPMS), which is said to be the most sensitive of nowavailable instruments, have been often used. The LOD (limit of detection) of ICP-MS for phosphorus, however, is still only at the several ppb level.

One of the other stable and sensitive methods is probably a spectrophotometric method coupled with some concentration method. Spectrophotometric methods for determining phosphate are usually based on the formation of a heteropolyacid, either unchanged or in its reduced form, Molybdenum Blue. The molar absorptivities of these heteropolyacids are generally less than $(1-2) \times 10^{4} \mathrm{dm}^{3} \mathrm{~mol}^{-1} \mathrm{~cm}^{-1}$. One possible way to increase the sensitivity of the spectrophotometric method is the use of the formation reaction of the ion associate of the heteropolyacid with a cationic dye, such as Malachite Green (MG) or Ethyl Violet (EV). When MG was used in an aqueous medium the molar absorptivity was about $8 \times 10^{4} \mathrm{dm}^{3} \mathrm{~mol}^{-1} \mathrm{~cm}^{-1} .1,2$ In the case of solvent-extraction methods with $\mathrm{EV}$ or $\mathrm{MG}$, the molar absorptivities

t Presented at the ITAS 94, August 23-28, 1994, HakodateSapporo, Japan. were highly increased, about $(25-27) \times 10^{4} \mathrm{dm}^{3} \mathrm{~mol}^{-1}$ $\mathrm{cm}^{-1} .3,4$ The solvent-extraction/spectrophotometric method with MG was very sensitive: the LOD was $0.1 \mathrm{ppb}$ when $50 \mathrm{~cm}^{3}$ of the sample solution was used. However, any further sensitivity enhancement is limited because of an increase in the absorbance of the reagent blank. Matsubara et al. reported on another concentration method based on the adsorption of the ion associate with MG on a membrane filter, such as a cellulose nitrate filter; more than $0.3 \mathrm{ppb}$ phosphorus was determined using $200 \mathrm{~cm}^{3}$ of the sample solution. ${ }^{5}$

In usual procedures for the concentration using membrane filters, a large volume of the sample solutions is required to obtain a high concentration efficiency, and several $\mathrm{cm}^{3}$ of an organic solvent for dissolving the membrane filters and measuring the absorbances are needed. Furthermore, a batch-wise procedure for precise measurements of the absorbances can be made only in the absorbance ranges from 0.1 to 0.8 , according to Twyman-Lothian's Law.

As mentioned above, the filtration concentration/ dissolution procedure reported so far has usually been limited to the determination of analytes at several ppb or sub-ppb levels, even when several hundreds of $\mathrm{cm}^{3}$ of sample were used. To break through the LOD of sub$\mathrm{ppb}$ and to overcome the defects of the usual concentration procedures with membrane filters, we 
adopted a flow-injection technique for the absorbance measurement, which has enabled us to measure small absorbances quite reproducibly while using a small volume of an analyte solution. Furthermore, the sample volumes could be reduced to several tens of $\mathrm{cm}^{3}$.

In this work, we report on a highly sensitive spectrophotometric method for determining phosphorus at concentrations at the ppt level using both small volumes of the sample solutions and an organic solvent (Methyl Cellosolve) and a tiny membrane filter for collecting the ion associate of molybdophosphate with MG. This ultra-high sensitivity has been achieved by re-examining the optimal reaction conditions, assembling an automatic measuring apparatus for small absorbances and developing a newly designed filtering apparatus. The proposed method is relatively simple and more sensitive than any other method already reported.

\section{Experimental}

\section{Reagents}

Standard phosphate solution. Potassium dihydrogen phosphate was dried to constant mass at $60^{\circ} \mathrm{C}$ under reduced pressure (about $400 \mathrm{~Pa}$ ) and dissolved $(0.2722 \mathrm{~g}$ ) in distilled water to give $100 \mathrm{~cm}^{3}$ of a solution $(2.00 \times$ $10^{-2} \mathrm{~mol} \mathrm{dm}^{-3}$ ); working solutions which were prepared by accurate dilution of the stock solution had to be prepared fresh daily and acidified with hydrochloric acid to about $0.003 \mathrm{~mol} \mathrm{dm}^{-3}$.

Reagent solution. A molybdate(Mo)-Malachite Green (MG) mixed-reagent solution (MG: $6 \times 10^{-5} \mathrm{~mol} \mathrm{dm}^{-3}$; Mo: $0.12 \mathrm{~mol} \mathrm{dm}^{-3}$; $\mathrm{HCl}: 2.7 \mathrm{~mol} \mathrm{dm}^{-3}$ ) was prepared as follows. First, $2.13 \mathrm{~g}$ of ammonium heptamolybdate, $\left(\mathrm{NH}_{4}\right)_{6}\left(\mathrm{Mo}_{7} \mathrm{O}_{24}\right) \cdot 4 \mathrm{H}_{2} \mathrm{O}$ (Merck), was transferred into a beaker and dissolved with $30 \mathrm{~cm}^{3}$ water. Then, $24 \mathrm{~cm}^{3}$ of concentrated hydrochloric acid and $10 \mathrm{~cm}^{3}$ of an MG solution containing $0.0028 \mathrm{~g}$ of Malachite Green oxalate were added. The solution was transferred into a $100 \mathrm{~cm}^{3}$ volumetric flask and diluted to the mark with water. About $12 \mathrm{~h}$ later after preparing a mixed-reagent solution, the solution was filtered through a cellulose nitrate membrane filter (pore size, $0.45 \mu \mathrm{m}$; diameter, $25 \mathrm{~mm}$ ). The filtrate was used as the reagent solution.

All of the chemicals used were of analytical reagent grade or the highest quality available. Highly purified water obtained by re-distilling with a non-boiling type quartz apparatus was used throughout.

\section{Apparatus}

A filtration concentration apparatus, which was newly designed for this work, is shown in Fig. 1. A filter holder having a hole ( $2 \mathrm{~mm}$ effective filtering diameter) was made of glass, holds a tiny membrane filter on it and contacts with a $50 \mathrm{~cm}^{3}$ glass separatory funnel. A tiny cellulose nitrate membrane filter (diameter: $9 \mathrm{~mm}$ ) was used. The filtration was carried out by suction with an aspirator.

A schematic diagram of a flow-injection system is

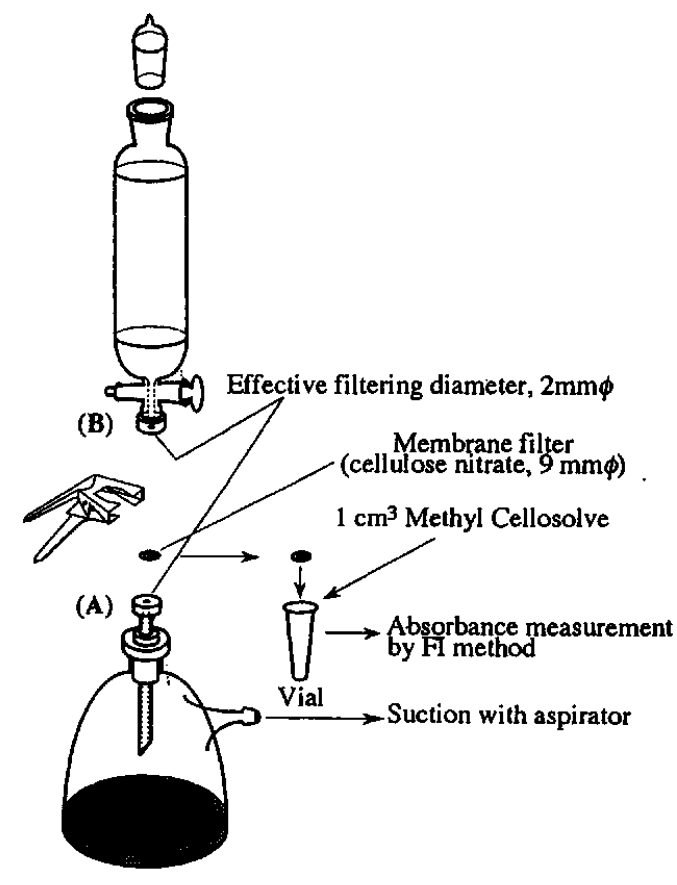

Fig. 1 Filtration/concentration apparatus.

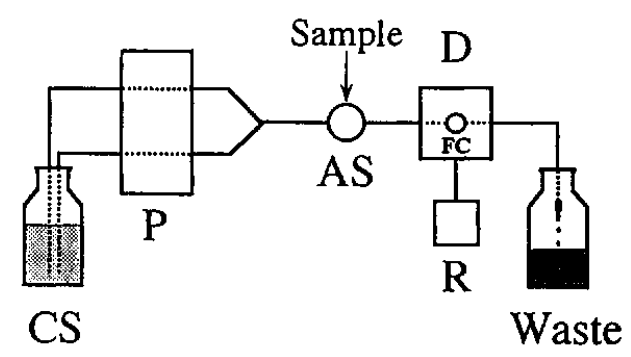

Fig. 2 Schematic diagram of the absorbance measurement system. CS, carrier solution (Methyl Cellosolve); P, pump $\left(0.5 \mathrm{~cm}^{3} \mathrm{~min}^{-1}\right)$; AS, autosampler (sample injection, $0.1 \mathrm{~cm}^{3}$ ); $\mathrm{D}, \mathrm{UV}-\mathrm{Vis}$ detector $(627 \mathrm{~nm})$; $\mathrm{R}$, recorder; FC, flow cell.

shown in Fig. 2. A double-plunger micropump (Sanuki Kogyo, DM2M-1024) was used to deliver the carrier, Methyl Cellosolve (2-methoxyethanol), at a flow rate of $0.5 \mathrm{ml} \mathrm{min}{ }^{-1}$. One tenth $\mathrm{cm}^{3}$ of samples was injected by an autosampler (System Instruments, Model 23). The absorbances at $627 \mathrm{~nm}$ were measured by a double-beam UV-Vis detector equipped with a $10-\mathrm{mm}$ flow cell $(8 \mu \mathrm{l})$, and recorded with a strip chart recorder (TOA Electronics, FBR-251A). All flow lines were made of poly(tetrafluoroethylene) (PTFE) tubing (0.5 $\mathrm{mm}$ i.d.); the length of the line from the autosampler to the flow cell was $30 \mathrm{~cm}$.

\section{Standard procedure}

Transfer $10-40 \mathrm{~cm}^{3}$ of a sample solution containing phosphorus as orthophosphate to the separatory funnel (Fig. 1). Add $1 \mathrm{~cm}^{3}$ of the mixed reagent solution (MG 
$6 \times 10^{-5} \mathrm{~mol} \mathrm{dm}^{-3} ; \mathrm{Mo} 0.12 \mathrm{~mol} \mathrm{dm}^{-3} ; \mathrm{HCl} 2.75 \mathrm{~mol} \mathrm{dm}^{-3}$ ) per $5 \mathrm{~cm}^{3}$ of a sample solution, mix it and stand it for $5 \mathrm{~min}$. Filter the solution through the membrane filter under suction. After filtration, wash the membrane filter with $10 \mathrm{~cm}^{3}$ of water, and then transfer the ion associate together with the membrane filter into a small polypropylene cone-type vial $\left(1.5 \mathrm{~cm}^{3}\right)$ containing $1 \mathrm{~cm}^{3}$ or less of Methyl Cellosolve. After dissolution of the membrane filter, measure the absorbance at $627 \mathrm{~nm}$ by the flow injection technique.

These procedures, except for that of the absorbance measurement, were carried out in a clean bench (Hitachi CCV-1301EC)

\section{Results and Discussion}

Development of a flow-through system for absorbance measurements

In general, commonly used filtration-dissolution methods have been performed by using 25 -mm diameter membrane filters; therefore, several $\mathrm{cm}^{3}$ of a dissolution solvent have been required to completely dissolve the membrane filters and to measure the absorbances with a common-type cell of $10-\mathrm{mm}$ path length. Such methods have some disadvantages in improving the sensitivity and precision: (a) they require a large volume of the sample and dissolution solvent, (b) the absorbance ranges are $0.1-0.8$ and (c) the reproducibility of the absorbance measurement is bad.

In this work we developed a new system for measuring the absorbances in order to overcome the disadvantages of the commonly used filtration-dissolution methods. This method enabled us to measure very minute absorbances, as small as $10^{-5}$, reproducibly by using only only $0.1 \mathrm{~cm}^{3}$ of the samples.

Figure 2 is a schematic diagram of the absorbance measurement system used in this work. The doubleplunger micropump was adopted in order to secure a non-pulse, stable and constant flow of the carrier for a long time. The autosampler was adopted so as to repeatedly inject small volumes of the samples precisely.

By using this system we could detect an absorbance change of $10^{-5}$; the relative standard deviation of five measurements of a colored sample showing $5 \times 10^{-4}$ absorbance was about $0.5 \%$.

\section{Design of a filtration apparatus for tiny membrane filters}

First, we made various types of the filtration apparatus by working CTFE [poly(chlorotrifluoroethylene)] and PTFE. The effect of the effective filtering diameter of the holder (A) in Fig. 1 on the absorbance of a reagent blank was examined by varying the diameter from $1 \mathrm{~mm}$ to $5 \mathrm{~mm}$. It was found that the smaller was the effective filtering diameter, the smaller was the absorbance of the reagent blank and the slower was the filtering speed. From these results, the diameter of the hole of the holder (A) was determined to be $2 \mathrm{~mm}$, as a compromise between both the filtering speed and the reagent blank.

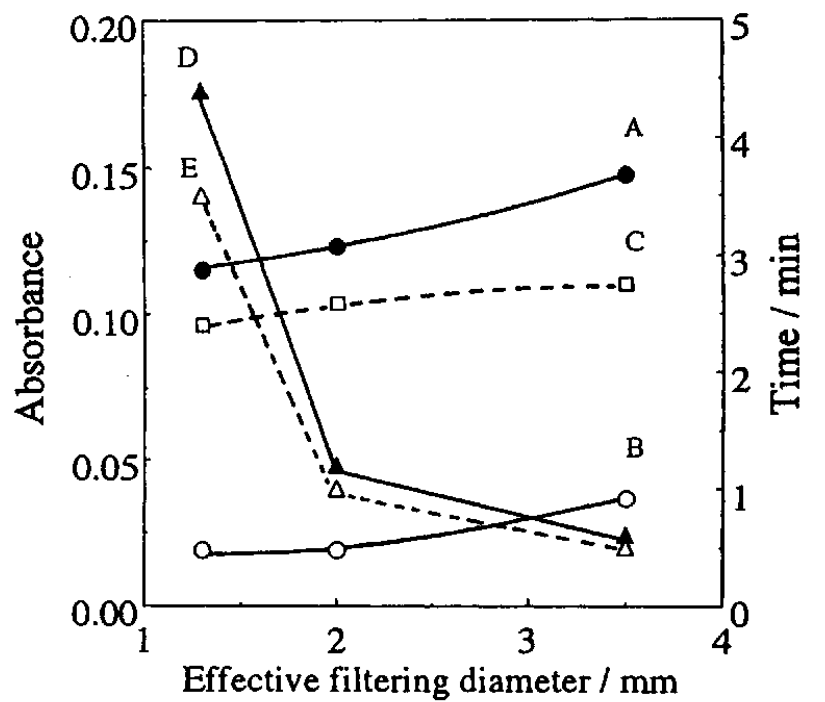

Fig. 3 Effect of the effective filtering diameter of the membrane filter. Sample, $20 \mathrm{~cm}^{3} ; \mathrm{A}, 3 \times 10^{-8} \mathrm{~mol} \mathrm{dm}^{-3}$ phosphate; B, reagent blank; C, difference between A and B; $D$, filtering time for sample; $E$, filtering time for reagent blank.

When a holder having a 2-mm hole was used, the 9-mm diameter membrane filter could be held on the holder as it was, even when $50 \mathrm{~cm}^{3}$ of the sample solution was filtered.

The effect of an effective filtering diameter of the foot of a separatory funnel, (B) in Fig. 1, was also examined. Figure 3 shows the result obtained using a holder (A) having a hole of 2-mm diameter. In this case, the results are similar to those in an experiment concerning the diameter of the holder (A). In further experiments, we adopted a 2-mm effective diameter of the foot of the separatory funnel and the holder as a compromise, considering the reagent blank and the filtering speed.

\section{Reaction conditions for the formation of an ion associate}

According to the present procedure for the ultra-trace determination method, the wavelength of the maximum absorption and the molar absorptivity of the ion associate dissolved in Methyl Cellosolve were $627 \mathrm{~nm}$ and $2.7 \times 10^{5} \mathrm{dm}^{3} \mathrm{~mol}^{-1} \mathrm{~cm}^{-1}$, respectively. These data were identical to those obtained by the procedure for normal concentrations of phosphorus as well as those reported by Matsubara et al. ${ }^{5}$ This indicates that the ion associate of molybdophosphate was almost quantitatively collected on the tiny membrane filter.

The effect of the Malachite Green concentration was examined. Both the absorbances of the reagent blank and the $3 \times 10^{-8} \mathrm{M}$ phosphate sample increased along with an increase in the concentration of MG; the differences in the absorbances between the sample and the reagent bank were almost identical at concentrations above $7.5 \times 10^{-6} \mathrm{~mol} \mathrm{dm}^{-3}$ of $\mathrm{MG}$. This indicates that the increase in the absorbance of the reagent blank with 
increasing the amount of MG is not caused by the ion associate of the heteropoly acid anion and MG, but rather, the ion associates formed between $\mathrm{MG}$ and the isopolymolybdate anion or chloride anion. In order to lower the absorbance of the reagent blank, $1 \times 10^{-5}$ mol dm ${ }^{-3} \mathrm{MG}$ was adopted in the present work. This MG concentration is one tenth or one thirteenth of those used in the previous methods. 2,5

The effect of the acidity was also examined. In almost all studies using ion associates of heteropolyacid with cationic dyes ${ }^{2-9}$, sulfuric acid has been used, as reported by Motomizu et al. ${ }^{2}$ The optimal concentration range of sulfuric acid, however, was very narrow and the reagent blank was large, compared with hydrochloric acid. Therefore, hydrochloric acid was used instead of sulfuric acid, aiming at lowering the reagent blank and improving the sensitivity. Adjusting the acidity of the solutions was very important both for the formation of the molybdophosphate and the ion associate and for a decrease in the reagent blank. Acidifying the solution allows MG to be in the protonated yellow form and to decrease the absorbance of the reagent blank. Figure 4 shows the results obtained by varying the concentrations of hydrochloric acid. In such acidity regions it has already been ascertained that molybdophosphate formed quantitatively. The relations between the absorbance and the hydrochloric acid concentration show two plateaus; the ratio of the absorbance corresponding to the two plateaus is $3: 2$, which indicates that the larger absorbances correspond to a $(3: 1)$ ion associate $\left(\mathrm{MG}^{+}\right)_{3^{-}}$ $\left(\mathrm{PMo}_{12} \mathrm{O}_{40}{ }^{3-}\right)$, and the smaller absorbances correspond to a $(2: 1)$ ion associate $\left(\mathrm{MG}^{+}\right)_{2}\left(\mathrm{HPMo}_{12} \mathrm{O}_{40}{ }^{2-}\right)$. With respect to the sensitive method, the higher plateau is preferable. When the hydrochloric acid concentrations were in the ranges from $0.45 \mathrm{~mol} \mathrm{dm}^{-3}$ to $0.55 \mathrm{~mol} \mathrm{dm}^{-3}$, the absorbances for the samples were almost identical, and the absorbances of the reagent blank were very small, about 0.02 . Therefore, the acidity was adjusted to $0.45 \mathrm{~mol} \mathrm{dm}^{-3}$ with hydrochloric acid. In previous work $^{2}$, the acidity was adjusted with sulfuric acid to be about $0.45 \mathrm{~mol} \mathrm{dm}^{-3}$.

The effect of the concentration of molybdate was examined by varying the concentrations from 0 to $0.08 \mathrm{~mol} \mathrm{dm}^{-3}$ of molybdate as Mo. The absorbances increased along with an increase in the concentration of molybdate, and the differences in the absorbance between the sample and the reagent blank were almost identical at concentrations above $2 \times 10^{-2} \mathrm{~mol} \mathrm{dm}^{-3} \mathrm{mo}-$ lybdate as Mo. In this work, $2 \times 10^{-2} \mathrm{~mol} \mathrm{dm}^{-3}$ of molybdate, which is one half of the concentration adopted in the previous work ${ }^{2}$, was chosen from the view point of a small absorbance of the reagent blank.

\section{Effect of filtering conditions}

The effect of the material and pore size of the membrane filters was tested in order to collect the ion associate quantitatively and to lower the absorbances of the reagent blank. Cellulose nitrate, cellulose acetate and poly(tetrafluoroethylene) were examined as possible

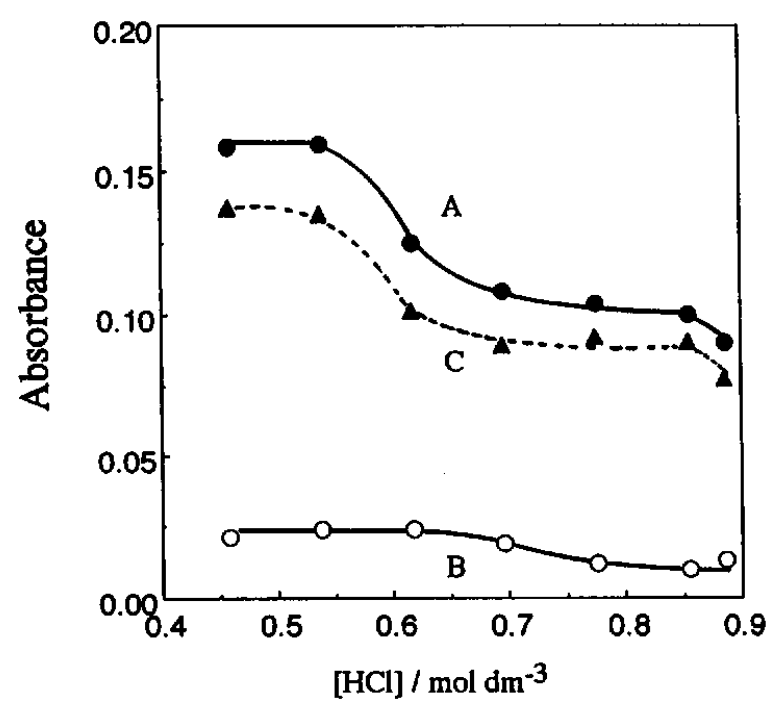

Fig. 4 Effect of the hydrochloric acid concentration. Sample, $20 \mathrm{~cm}^{3} ; \mathrm{A}, 3 \times 10^{-8} \mathrm{~mol} \mathrm{dm}^{-3}$ phosphate; B, reagent blank; C, difference between A and B. Mo, $0.033 \mathrm{~mol} \mathrm{dm}^{-3}$; MG, $1 \times 10^{-5} \mathrm{~mol} \mathrm{dm}^{-3}$.

materials for the membrane filters. The best collection of the ion associate was achieved by using cellulose nitrate filters having a $1.0 \mu \mathrm{m}$ pore size.

The concentration efficiency was studied by varying the volumes of the sample solution under the condition that the ratio of the volume of the mixed reagent solution to the volume of the sample solution be identical. The obtained results are shown in Fig. 5. The absorbances of the reagent blank were identical when more than $10 \mathrm{~cm}^{3}$ of the reagent-blank solutions was filtered, whereas the absorbance of a sample solution containing $6 \times 10^{-9} \mathrm{~mol} \mathrm{dm}^{-3}$ phosphate increased linearly with increasing the volume of the sample solution up to $40 \mathrm{~cm}^{3}$. These results indicate that the membrane filter is easily saturated with ion associates containing MG, which is responsible for the reagent blank and is probably the ion associate of isopolymolybdate with MG. They also show that the ion associate of molybdophosphate with MG is strongly adsorptive on the membrane filter and can adsorb linearly along with an increase in the total amount of phosphorus in the samples.

To explain the results shown in Fig. 5, we assume that the membrane filter possesses two kinds of sites to hold ion associates on it: one is a strong site, which can hold both the ion associates of molybdophosphate and isopolymolybdate with MG; the other is a weak site, which can hold only the ion associate of molybdophosphate. On the basis of such an assumption we can explain why the absorbance difference between the sample and the reagent blank was small when $10 \mathrm{~cm}^{3}$ of the sample was used. When samples contain no molybdophosphate the ion associate of isopolymolybdate with MG occupies all of the strong sites. As the molybdophosphate increases, the ion associate of 


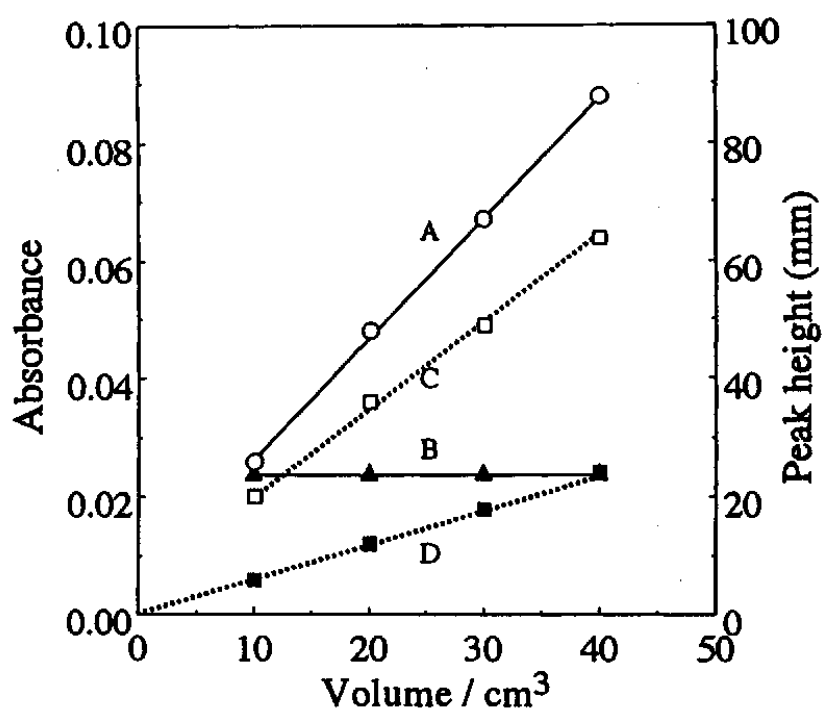

Fig. 5 Effect of the volume of the sample and the reagent blank solution. A, $6 \times 10^{-9} \mathrm{~mol} \mathrm{dm}^{-3}$ phosphate; ref., Methyl Cellosolve; B, reagent blank, ref., Methyl Cellosolve. C and $D$, calculated values (see the text).

isopolymolybdate occupying the strong sites is replaced by the ion associate of molybdophosphate. When the molybdophosphate is present in an excess amount of the strong sites, the ion associate of molybdophosphate occupies all of the strong sites and a few weak sites. The ion associate of molybdophosphate occupying the weak sites corresponds to the absorbance difference between the sample and the reagent blank, as is shown in Fig. 5. Therefore, phosphate below about $6 \times 10^{-9} \mathrm{~mol} \mathrm{dm}^{-3}$ can not be detected when $10 \mathrm{~cm}^{3}$ of the sample solution is used.

The absorbance corresponding to $10 \mathrm{~cm}^{3}$ of the phosphate solution was calculated to be 0.02 from the slope of line $A$ in Fig. 5. This absorbance and the multiplied ones are subtracted from the absorbances of line $A$, which gives the dotted line (D). The absorbances of line D correspond to the phosphate in the reagent solution used in this work. The dotted line $\mathrm{C}$ was obtained by subtracting the absorbance of line $D$ from those of line $A$; that is, line $C$ shows net absorbances corresponding to the phosphate contained in the sample solutions.

The absorbance differences between lines B and D correspond to the lowest determinable limit (LDL) at concentrations below which we can not observe the absorbance difference between a sample and a reagent blank. The LDL values were calculate to be $160 \mathrm{ppt}$, $70 \mathrm{ppt}, 19 \mathrm{ppt}$ and 0 , respectively, for $10 \mathrm{~cm}^{3}, 20 \mathrm{~cm}^{3}$, $30 \mathrm{~cm}^{3}$ and $40 \mathrm{~cm}^{3}$ of the sample solution. The calculated LDL values agreed with the experimental values. For example, the experimental LDL value for $20 \mathrm{~cm}^{3}$ of the sample solution was $75 \mathrm{ppt}$ at concentrations above which a calibration graph was linear.

In conclution, we can find from Fig. 5 that a procedure

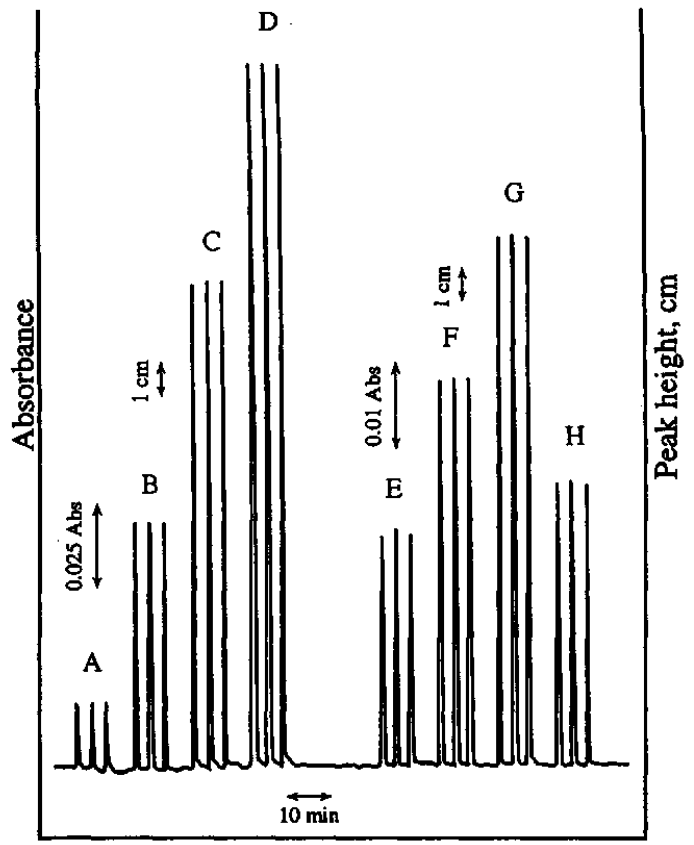

Fig. 6 Example of flow-injection signals for phosphate determination. Samples, A-D $20 \mathrm{~cm}^{3}, \mathrm{E}-\mathrm{H} 40 \mathrm{~cm}^{3}$. Phosphorus $\left(\mathrm{ng} \mathrm{dm}^{-3}\right)$, A and E, $0 ; \mathrm{B}, 370 ; \mathrm{C}, 740 ; \mathrm{D}, 1110 ; \mathrm{F}, 62$; $\mathrm{G}, 124 ; \mathrm{H}, 18$. MG, $1 \times 10^{-5} \mathrm{~mol} \mathrm{dm}^{-3}$; $\mathrm{Mo}, 0.02 \mathrm{~mol} \mathrm{dm}^{-3}$; $\mathrm{HCl}, 0.46 \mathrm{~mol} \mathrm{dm}^{-3}$.

using $40 \mathrm{~cm}^{3}$ of the sample is best from the view point of high sensitivity without any increase in the reagent blank.

\section{Calibration graph and detection limit}

Calibration graphs were made by using phosphate solutions from $10 \mathrm{~cm}^{3}$ to $40 \mathrm{~cm}^{3}$ of the sample solution. Examples of the profile of flow signals are shown in Fig. 6. The calibration graph was linear over the ranges from 0.018 to $1 \mathrm{ng} \mathrm{cm}^{-3}$ of phosphorus when $40 \mathrm{~cm}^{3}$ was used. The absorbance of the reagent blank was about 0.025 . The detection limit corresponding to two times of the standard deviation of the absorbances of the reagent blank was $1 \times 10^{-10} \mathrm{~mol} \mathrm{dm}^{-3}(3 \mathrm{ppt})$ for $40 \mathrm{~cm}^{3}$ of samples. The determinable ranges obtained by using $20 \mathrm{~cm}^{3}$ and $40 \mathrm{~cm}^{3}$ of the sample solutions were about $(0.08-5) \mu \mathrm{g} \mathrm{dm}^{-3}$ and about $(10-1000) \mathrm{ng} \mathrm{dm}^{-3}$, respectively.

\section{Effect of foreign ions}

Interference from foreign ions was examined. Arsenic(V) severely interfered with the determination of phosphorus, giving a positive error, because arsenic(V) formed molybdoarsenate, which formed an ion associate with MG to be collected on the membrane filter under the same conditions as in phosphorus. Silicate, vanadate(V) and germanium (IV) at concentrations of $3 \times 10^{-7}$ mol dm $\mathrm{dm}^{-3}$ and commonly existing cations and anions at concentrations of $10^{-5} \mathrm{~mol} \mathrm{dm}^{-3}$ did not interfere with the determination of phosphorus. 
Table 1 Determination of phosphate in purified water samples

\begin{tabular}{lccc}
\hline $\begin{array}{c}\text { Sample } \\
\left(40 \mathrm{~cm}^{3}\right)\end{array}$ & Absorbance ${ }^{\mathrm{a}}$ Peak height/ & $\begin{array}{c}\text { Phosphorus } \\
\mathrm{mm}\end{array}$ & $\begin{array}{c}\text { contents/ } \\
10^{-12} \mathrm{~g} \mathrm{~cm}^{-3}\end{array}$ \\
\hline Redistilled water $^{\mathrm{b}}$ & 0.0258 & 65.0 & - \\
Distilled water $^{\mathrm{c}}$ & 0.0283 & 70.2 & 5.0 \\
Milli Q $^{\mathrm{d}}$ & 0.0542 & 135.2 & 76.0 \\
Milli Q $^{\mathrm{e}}$ & 0.0350 & 87.0 & 24.0 \\
De-ionized water & 0.0589 & 139.9 & 90.0 \\
\hline
\end{tabular}

a. Reference: Methyl Cellosolve.

b. De-ionized and distilled water was distilled with a nonboiling type quartz apparatus. This was used as reagent blank.

c. De-ionized and distilled water.

d. De-ionized and distilled water was treated with a Milli Q Lab.

e. De-ionized and distilled water was treated with another Milli Q Lab.

\section{Determination of phosphate in purified water samples}

Trace amounts of phosphate in purified-water samples were determined by the proposed method. The results are shown in Table 1. Redistilled water gave a smaller absorbance, and was temporarily used as the reagent blank. Though deionized and distilled water gave relatively small absorbances, they were scattered between different lots. Redistilled water, however, gave almost identical absorbances, even in different lots. We therefore used the redistilled water as the reagent blank, and the phosphorus contents existing as orthophosphate were determined, as shown in Table 1.

\section{References}

1. K. Itaya and M. Ui, Anal. Chim. Acta, 14, 361 (1966).

2. S. Motomizu, T. Wakimoto and K. Tôei, Analyst [London], 108, 361 (1983).

3. S. Motomizu, T. Wakimoto and K. Tôei, Clin. Chim. Acta, 138, 329 (1982).

4. S. Motomizu, T. Wakimoto and K. Tôei, Talanta, 31, 235 (1984).

5. C. Matsubara, Y. Yamamoto and K. Takamura, Analyst [London], 112, 1257 (1987).

6. S. Motomizu, T. Wakimoto and K. Tôei, Talanta, 30, 333 (1983).

7. S. Motomizu and M. Oshima, Analyst [London], 112, 295 (1987).

8. S. Motomizu, M. Oshima and K. Araki, Analyst [London], 115, 1627 (1990).

9. C. Matsubara, K. Yoshihara, N. Kobayashi, Y. Yonehara and K. Takamura, Bunseki Kagaku, 38, 627 (1989).

(Received October 3, 1994)

(Accepted November 28, 1994) 